\title{
Mexico and China in the US manufacturing market: An empirical analysis
}

México y China en el mercado manufacturero estadounidense: un análisis empírico

\author{
${ }^{1}$ Universidad Autónoma Metropolitana, México \\ ${ }^{2}$ Colegio de la Frontera Norte, México
}

Víctor M. Cuevas Ahumada $^{1 *}$, Cuauhtémoc Calderón Villarreal ${ }^{2}$

Received April 27, 2018; accepted August 30, 2019

Available online September 5, 2019

\begin{abstract}
This paper conducts a disaggregated comparative analysis of China's and Mexico's export dynamism in the US manufacturing market over the period 1994-2017 and, against this backdrop, it estimates a dynamic panel data model through two econometric techniques to show the impact of key variables on Mexico's export performance across manufacturing subsectors of different technology categories. Export performance is measured in terms of import market shares in the US and numerous econometric issues are addressed to produce reliable evidence. In addition to capturing some heterogeneity among different manufacturing subsectors, this study shows that: (i) a depreciation of the real exchange rate calculated for each subsector worsens (rather than improves) Mexico's export performance, which is

\footnotetext{
*Corresponding author.

E-mail address: victorcuevasahumada@yahoo.com.mx (V. Cuevas Ahumada)

Peer Review under the responsibility of Universidad Nacional Autónoma de México. 
likely due to the high import content of Mexican manufacturing exports; (ii) a fall in domestic unit labor costs has a positive impact on Mexico's export performance, which highlights the importance of raising labor productivity faster than wages; and (iii) a reduction in US unit labor costs deteriorates Mexico's export performance.

JEL codes: C33, F14, L60

Keywords: Manufacturing exports; Panel data models; Mexico; China

\section{Resumen}

En este trabajo se realiza un análisis comparativo desagregado del dinamismo exportador de México y China en el mercado estadounidense de manufacturas durante el período 1994-2017 y se estima un modelo dinámico de datos en panel mediante dos métodos econométricos, mostrando así el impacto de variables clave en el desempeño exportador mexicano por subsectores de diferente categoría tecnológica. El desempeño exportador se mide mediante cuotas de mercado de importación de Estados Unidos y diversos problemas econométricos son resueltos para generar evidencia sólida. Además de capturar la heterogeneidad entre subsectores manufactureros, se demuestra que: (i) una depreciación de la paridad real calculada para cada subsector deteriora (lejos de mejorar) el desempeño exportador mexicano, lo que es atribuible al alto contenido importado de las exportaciones manufactureras, (ii) una caída en los costos laborales unitarios de México estimula el desempeño exportador del país, lo que subraya la importancia de elevar la productividad laboral por encima de los salarios, y (iii) una baja en los costos laborales unitarios estadounidenses empeora el desempeño exportador nacional.

Código JEL: C33, F14, L60

Palabras clave: Exportaciones manufactureras; Modelos de datos en panel; México; China

\section{Introduction}

The purpose of this paper is twofold. First, to carry out a comparative analysis of China's and Mexico's export dynamism in the US manufacturing market by technology category and subcategory of products during the 1994-2017 period. Second, to estimate a dynamic panel data model through two econometric methods: Feasible Generalized Least Squares (FGLS) with cross-section weights, on the one hand, and the Arellano-Bond Generalized Method of Moments (GMM), on the other. By means of these two techniques, we evaluate the impact of some key variables on Mexico's export performance across different manufacturing sectors. The selection of explanatory variables relies on three basic elements: economic theory, previous empirical work, and the obtainability of disaggregated data. As shall be seen, several data and econometric issues are addressed to produce a specification that is statistically appropriate as well as theoretically plausible. 
To get a proxy for export performance, China's and Mexico's import market shares (IMSs) in the US market are estimated over the reference period for four categories and nine subcategories of manufacturing products. To carry out such a task, Lall's (2000) methodology and the Standard International Trade Classification (SITC-Revision 3) system are used. The relative performance of each Chinese and Mexican manufacturing category in the US market is assessed through shifts in IMSs and through changes in the IMS average growth rates across different sample periods. Moreover, for every sample period we calculate the variation coefficient of IMS growth rates, which represent an unbiased and normalized measure of dispersion. The evidence points to the conclusion that China's IMS growth rates during the period 1994-2017 are in most cases higher and more stable than Mexico's.

Against this backdrop, we proceed to estimate a parsimonious dynamic panel data model consisting of supply- and demand-side variables, along with a control variable to reduce the omitted variable bias. Such a model draws on Fagerberg (1988) and is aimed at providing evidence about some major determinants of Mexican IMS dynamics in the US. As we explain in Section 5, due to the lack of fully disaggregated data for some of the variables of the model, the estimation period had to be restricted in this case, which means that it runs from 2007 to 2017. In addition to capturing some degree of heterogeneity among industries of different technology rankings, the evidence across the two econometric methods consistently show that: (i) a real depreciation of the subsector-specific exchange rate (of the peso vis-à-vis the US dollar) reduces, rather than increases, Mexico's IMSs in the US, which is presumably due to the large import content of Mexican manufacturing exports; (ii) lower unit labor costs (ULCs) in Mexico raise its IMSs in the US; and (iii) reduced ULCs in the US, by contrast, bring down Mexican IMSs given that US manufacturing firms become relatively more competitive. These findings highlight two fundamental problems of the Mexican economy: (i) the overwhelming reliance of the export-oriented manufacturing industries on foreign suppliers of intermediate inputs, capital stock and technology, which would explain the counterintuitive effect of currency depreciation on the country's export performance, and (ii) the need to increase labor productivity faster than wages so as to reduce ULCs, improve IMSs and cope with Chinese competition in the US market more effectively. In this context, Mexico's low investment in high-quality formal education and in adequate training programs represents a major obstacle for faster productivity growth.

The remaining of this paper is organized as follows. Section 2 is a disaggregated IMS analysis showing the extent to which different categories and subcategories of Mexican manufacturing products are struggling in the US, especially when their performance is compared with that of the Chinese manufactures. Section 3 is an overview of the recent econometric work on the determinants of manufacturing exports. Section 4 deals with the specification of $t$ 
he panel data model while Section 5 estimates it through two econometric techniques and interprets the findings. The last section examines the policy implications.

\section{Mexico and China in the US Market: A disaggregated analysis}

Several papers analyze the competition between Mexico and China in the US manufacturing market (Mesquita, 2007; Gallagher et al., 2007; Gereffi, 2009; Lin, 2015). Mesquita (2007) argues that China's international competitiveness, which is based on resource endowments, labor productivity growth, government incentives, and scale factors such as land area and population size, poses a significant threat to the manufacturing industry of Mexico and other Latin American countries. According to Gereffi (2017), another major factor behind China's success in the US market lies in the implementation of a model of industrial organization, known as supply-chain cities, that has allowed the Chinese manufacturing industry to achieve scale economies and play a more strategic role in the Global Value Chains (GVCs). In this context, shortly after entering the World Trade Organization (WTO) in December 2001, China notably began to perform better than Mexico in the US manufacturing market and this trend continued until 2007 (Gallagher et al., 2007; Gereffi, 2009), when the global economic crisis emerged. After 2007, China started to lose some steam while Mexico recovered some ground in the US manufacturing market (Lin, 2015). Although these findings are reasonably consistent with the evidence provided here, we also calculate import market shares growth rates and a measure of volatility for this variable, among other differences.

To compare China's and Mexico's export dynamism with greater detail, Lall's (2000) methodology and the Standard International Trade Classification (SITC-Revision 3) system are utilized. Therefore, each country's manufacturing exports are classified according to technology characteristics. Such an analysis is performed at the three-digit SITC level to decompose each country's manufacturing exports into a significant number of groupings, which are then assigned to four categories and nine sub-categories. Specifically, exports of manufactured goods are broken down into the following categories: resource based, low technology, medium technology, and high technology. As shown in Table 1, each category is further disaggregated into a few sub-categories for analytical purposes. The same scheme is used to decompose US manufacturing imports from the rest of the world, so as to estimate China's and Mexico's import market shares (IMSs) in the US by category and subcategory of products. Formally speaking, let $X_{i j t}$ be the exports of a category of goods $i$ from country $j$ to the US at time $t$, and Mit be the total US imports of a category of goods $i$ at time $t$. Therefore, the share in the US import market of a category of goods $i$ exported from country $j$, denoted IMSijt, is simply calculated as: $I M S_{i j t}=\left(X_{i j t /} M_{i t}\right) * 100$. Table 1 depicts the results of this exercise for selected years between 1994 and 2017: 
Table 1

China's and Mexico's shares in the US manufacturing imports by technology category and subcategory (\%)

\begin{tabular}{ccccccccc}
\hline \multicolumn{1}{c}{ China } \\
\hline & 1994 & 2002 & 2008 & 2017 & 1994 & 2002 & 2008 & 2017 \\
RB & 1.64 & 4.25 & 7.58 & 10.63 & 4.29 & 4.34 & 3.78 & 6.70 \\
RB1 & 1.48 & 6.00 & 13.19 & 11.67 & 4.28 & 7.60 & 9.05 & 12.28 \\
RB2 & 1.78 & 3.11 & 5.28 & 9.85 & 4.30 & 2.21 & 1.62 & 2.46 \\
LT & 20.64 & 26.80 & 41.46 & 40.77 & 5.40 & 9.12 & 6.37 & 7.43 \\
LT1 & 23.40 & 24.93 & 41.79 & 41.32 & 4.47 & 9.64 & 4.66 & 4.21 \\
LT2 & 17.89 & 28.26 & 41.24 & 40.45 & 6.32 & 8.71 & 7.49 & 9.38 \\
MT & 2.79 & 6.81 & 10.40 & 13.15 & 9.03 & 14.43 & 13.92 & 21.15 \\
MT1 & 0.31 & 0.98 & 2.92 & 4.60 & 7.42 & 15.67 & 16.83 & 29.06 \\
MT2 & 1.07 & 5.12 & 8.26 & 12.78 & 5.15 & 5.67 & 5.03 & 6.93 \\
MT3 & 5.57 & 13.60 & 17.19 & 20.34 & 11.50 & 15.33 & 15.17 & 18.77 \\
HT & 3.68 & 12.22 & 27.97 & 35.70 & 7.48 & 13.45 & 12.26 & 12.17 \\
HT1 & 3.78 & 15.21 & 36.53 & 48.03 & 8.23 & 15.97 & 15.58 & 15.18 \\
HT2 & 3.18 & 3.42 & 4.49 & 5.28 & 3.41 & 6.02 & 3.16 & 4.73
\end{tabular}

Notes: RB=Resource based, RB1=Agro/forest based, RB2=Other products, $\mathrm{LT}=$ Low Technology, LT1=Textile/fashion cluster, $\mathrm{LT} 2=$ Other products, MT=Medium technology, MT1=Automotive products, MT2=Process products, MT3=Engineering industries, HT=High technology, HT1=Electronic and electrical products, and HT2=Other products. The import market share in the US of, say, Chinese high-technology products, is the percentage participation of Chinese high-technology exports in total US high-technology imports. Lall's (2000) methodology and the Standard International Trade Classification (SITC) system are employed to identify manufacturing exports at the three-digit level and to classify them, based on their technological intensity, into four categories and nine sub-categories. The same procedure applies to US manufacturing imports.

Source: Own estimations based on data from the International Trade Administration of the US Department of Commerce.

Table 1 allows us to analyze three important stages: (i) Mexico's manufacturing export expansion following the enactment of the North American Free Trade Agreement (NAFTA) on January 1, 1994; (ii) China's remarkable manufacturing export growth, mainly after its accession to the WTO in late 2001, which appears to slow down the Mexican export expansion in the following years; and (iii) the somewhat mixed performance of Chinese and Mexican manufacturing industries in the US market after the emergence of the US economic recession in December 2007. 
Broadly speaking, China increased its IMS in every category and subcategory of goods considered throughout the period 1994-2017. During this period, the most noticeable progress in terms of IMS gained in the US was in high-technology products, mainly in the electronics and electrical industry (i.e., office machines, automatic data processing equipment, telecommunications equipment, advanced power generating machinery, and the most sophisticated types of electrical machinery and apparatus). Nevertheless, China also achieved considerable market success in: (i) medium-technology manufactures such as parts and accessories of motor vehicles, motorcycles and cycles, synthetic fibers, plastics and chemical products, electrical machinery and equipment, non-electrical machinery, and household type equipment; (ii) low-technology manufactures such as textile goods, footwear, travel goods, furniture and bedding, and toys and sporting goods; and (iii) resource-based manufactures such as processed food and vegetables, snack foods and other edible products, rubber manufactures, and non-metallic mineral commodities (e.g., glass, lime, cement and fabricated construction materials). Breaking down the analysis of Table 1 into different stages, we can see that the most flourishing period for China started with its entrance to the WTO and ended with the advent of the US economic slowdown.

Table 1 also shows the mixed results achieved by Mexico over the 1994-2017 period. On the positive side, Mexican automotive products almost quadrupled their IMS in the US. In stark contrast to China, Mexico performed relatively well not only in the auto parts and accessories industry, but also in standard motor vehicles, special-purpose motor vehicles (primarily for the transport of goods), and even road vehicles (such as buses and tractors for semi-trailers). In some other categories and sub-categories of goods Mexico did not perform as well as China but could still gain a little ground or, at least, hold relatively steady in the US market. Some noticeable examples of this are: (i) high-technology products such as power generating machinery, automatic data process machines, telecommunications equipment, and electrical machinery apparatus; (ii) process products such as dyeing, tanning and coloring materials; perfumery and cosmetics; and plastics in primary and non-primary form; (iii) engineering industries such as electrical machinery and equipment, non-electrical machinery, and household type equipment; (iv) low-technology products outside the textile/fashion cluster, such as iron and steel products, manufactures of metals, and furniture and bedding accessories; and (v) resourced-based products such as processed food and vegetables, alcoholic beverages, snack food and other edible products, and rubber manufactures.

On the negative side, from 2002 to 2017 the Mexican textile/fashion cluster experienced a significant market share reduction, which basically explains the lackluster performance of Mexico's low-technology products in the US import market. During the same period (2002-2017), Mexico was surpassed by China in two categories: resource-based and hightech products. Particularly, China's high-technology industry got way ahead of Mexico's. In 
2017, for instance, China held an IMS in the US that was almost three times as large as that of Mexico. Another reason for concern is that, although Mexico remains a dominant player in automotive products, China has been challenging Mexico in the other two subcategories of the medium-technology sector: process products and engineering industries. On balance, we can see that the best years for Mexico were between 1994 and 2002, whereas its most complicated years concurred with China's export upsurge between 2002 and 2008.

\section{Import market-share average growth rates and their estimated variation coefficients}

The Chinese and Mexican IMS average growth rates in the US are estimated for each technology category and for three sample periods: 1995-2001, 2002-2007 and 2008-2017. To provide more valuable insights, we also calculate the volatility of the IMS growth rates in every case. Along these lines, we show the changes in these two indicators stemming from the entry into force of NAFTA,1 China's accession to the WTO, and the emergence of the US economic recession in December of 2007. The volatility of the IMS growth rates is calculated by way of variation coefficients, which are obtained as follows:

$$
\mathrm{ECV}_{\mathrm{ij}}=\left(\mathrm{S}_{\mathrm{ij}} / \overline{\mathrm{Y}}_{\mathrm{ij}}\right)(1+1 / 4 \mathrm{~N})
$$

where ECVij denotes the estimated coefficient of variation of the IMS growth rate corresponding to export category $i$ from country $j, S i j$ is the sample standard deviation of the IMS growth rate of export category $i$ from country $j, \bar{Y} i j$ is the sample average growth rate of the IMS corresponding to export category $i$ from country $j$, and $N$ is the sample size. Therefore, $(1+1 / 4 N)$ is the small sample bias-correction factor provided by Sokal and Rohlf (1995). In such a context, for a sample of size $N$ we obtain an unbiased and normalized measure of dispersion, which is useful for comparison purposes. See Table 2:

Table 2

Chinese and Mexican growth rates of import market shares by technology category over different time intervals: sample averages and coefficients of variation

\begin{tabular}{crrrrrr}
\hline \multicolumn{3}{c}{ China } & \multicolumn{3}{c}{ Mexico } \\
\hline & $1995-2001$ & $2002-2007$ & $2008-2017$ & $1995-2001$ & $2002-2007$ & $2008-2017$ \\
RB & 10.94 & 10.97 & 4.20 & 1.42 & -1.61 & 5.67 \\
& & & & & $(2.71)$ & $(1.62)$
\end{tabular}

${ }^{1}$ Although NAFTA became effective in 1994, the first sample period starts in 1995 because one observation is lost after calculating the growth rates of IMSs for China and Mexico. 


\begin{tabular}{|c|c|c|c|c|c|c|}
\hline \multirow[t]{2}{*}{ LT } & 3.57 & 7.43 & 0.77 & 9.15 & -6.23 & 1.23 \\
\hline & $(0.71)$ & $(0.51)$ & (7.29) & $(1.02)$ & $(0.26)$ & (2.8) \\
\hline \multirow[t]{2}{*}{ MT } & 10.51 & 8.51 & 2.76 & 7.51 & -0.007 & 4.07 \\
\hline & $(0.41)$ & $(0.75)$ & $(2.42)$ & $(0.87)$ & $(72.0)$ & (1.33) \\
\hline \multirow[t]{2}{*}{ HT } & 13.99 & 17.69 & 2.87 & 9.53 & -1.17 & -0.24 \\
\hline & $(0.27)$ & $(0.65)$ & $(1.55)$ & $(0.83)$ & $(5.48)$ & (19.82) \\
\hline
\end{tabular}

Source: Own estimations based on data from the International Trade Administration of the US Department of Commerce.

According to Table 2, China's performance in terms of IMS growth has been noteworthy, mainly in the first two intervals considered: 1995-2001 and 2002-2007. Taking all technology categories into account, China's best period was from 2002 to 2007, which lies between its arrival to the WTO and the beginning of the US economic slowdown. During this period, Chinese high-tech industry was by far the most vigorous one, as its IMS in the US rose at an average annual rate of $17.69 \%$. Although to a lesser extent, resource-based, low-technology and medium-technology manufactures were very dynamic, given that their IMS growth rates for this period (2002-2007) averaged 10.97, 7.43 and $8.51 \%$ per year, respectively. Over the last period (2008-2017), Chinese manufacturing industries certainly lost some steam but, in every case, continued to increase their IMSs in the US.

With the notable exception of the resource-based industries, Mexico's most successful period was from 1995 to 2001, lying between the NAFTA implementation and the onset of the Chinese export boom. During these years (1995-2001), Mexico's low- and high-technology manufactures saw their IMSs grow at an average annual rate of 9.15 and $9.53 \%$, respectively. Medium-technology manufactures displayed some impetus as well, given that its share in the US import market increased at an average annual rate of $7.51 \%$. In fact, the resource-based industries were the only ones having a relatively sluggish performance during the first years of NAFTA. Nonetheless, we must highlight the remarkable performance of the resource-based industries during the 2008-2017 period, given the average annual growth rate of 5.67\% that these industries reported. 
The least dynamic period for Mexico started immediately after China became a member of the WTO in December of 2001, which is consistent with the notion that the Chinese rise in the US market has been crowding out Mexican export growth. Over the 2002-2007 period, Mexico's resourced-based, low-technology, high-technology and even medium-technology manufactures exhibited negative growth rates of their IMSs on average. In the last period under consideration (2008-2017), the Mexican resource-based, low-technology and medium-technology manufactures recovered some dynamism in the US market to different degrees. The IMS of the high-tech industry, however, continued to exhibit a negative average annual growth rate.

Finally, the estimated coefficients of variation shown in Table 2 indicate that, on average, China's IMS growth rates were not only higher but also more stable than Mexico's. The higher volatility of the Mexican IMS growth rates makes government policies at the national and local level more critical, given their potential impact on export performance over the shortand long-term horizons. The most notable exception is the Mexican medium-technology sector during the period 2008-2017, which registered a higher and less volatile IMS growth rate than its Chinese counterpart.

\section{Previous econometric work}

As stated at the outset, the second objective of this paper is to evaluate the impact of some key variables on Mexico's export performance across different manufacturing industries. As explained above, we resort to IMSs in the US as a measure of export performance for each manufacturing subsector. To increase the IMS of, say, high-tech products, it is necessary that Mexican exports of high-tech products grow faster than the corresponding US imports. Along these lines, this section mostly relies on the econometric evidence concerning the determinants of manufacturing exports.

Export functions are commonly specified under one of the following four approaches: (i) gravity models of trade, (ii) augmented gravity models of trade, (iii) standard demand models, and (iv) amplified export models comprising demand- and supply-side variables. The traditional gravity trade model postulates that exports volumes from country A to country B are a positive function of the countries' economic sizes and a negative function of the transportation costs involved (Tinbergen, 1962). The augmented gravity trade equations take account of other important factors, such as shared borders of the trading partners, common language, and infrastructure (Bayoumi and Eichengreen, 1997; Bougheas, Demetriades, and Morgenroth, 1999). To provide the gravity trade equations with greater explanatory power, some authors introduce variables that are no longer related to space and geography, such as exchange rates and prices (Soloaga and Winters, 2001; Martínez-Zarzoso and Nowak-Lehmann, 2002). 
The third strand of the literature is the one embodied by standard demand models, which posit export volumes as a function of the real exchange rate and external demand. External demand is usually measured by the level of economic activity abroad or by the total amount of imports from the nation's major trading partners. In the case of the developing economies, the evidence provided by Reinhart (1995), Senhadji and Montenegro (1999) and Garcés (2008) suggests that: (i) exports are more responsive to external demand than to changes in relative prices, and (ii) exchange rate depreciation raises exports by lowering their foreign-currency price. One caveat to this conclusion is the evidence that the greater importance of GVCs has significantly altered the relationship between real exchange rate movements and manufacturing exports (Swarnali, Appendino, and Ruta, 2017; Cheng et al., 2016).

Hybrid models consisting of supply- as well as demand-side variables represent the fourth strand of the literature. The export function formulated by Fagerberg (1988) combines supply- and demand-side variables. Under Fagerberg (1988) primal specification, the ratio of exports to foreign income plays the role of dependent variable (rather than export volumes). Put differently, $X / Y^{*}$ would be the dependent variable of the export function, where $X$ and $Y^{*}$ denote export volumes and foreign income, respectively. The explanatory variables are relative prices, technological competitiveness and a measure of productive capacity.

The relevance of incorporating supply-side variables in export functions is pointed out by Riedel (1998), who shows that working with only demand-side variables gives rise to miss-specification problems and thus biased estimates of relative price and external demand elasticities. Riedel's (1988) contribution further encouraged the use of amplified export functions comprising demand- and supply-side variables, such as labor productivity and wages. In the case of developing economies some examples stand out. Based on data from the Argentinian economy, Catão and Falsetti (2002) show that higher productive capacity fosters manufacturing exports and vice versa. Moreover, Mbaye and Golub (2002) find that increasing unit labor costs (ULCs) lower manufacturing exports in the case of Senegal. The empirical evidence provided by Aysan and Hacihasanoglu (2007) points to the same conclusion in the case of Turkey.

Other authors establish the positive interaction between technology-related variables (i.e., number of patents granted and research and development (R\&D) expenditure) and exports (Montobbio and Rampa, 2005; Menji, 2010). Lastly, developing country's manufacturing exports are closely related to Foreign Direct Investment (FDI), given that it generates production capacity, technological transfers and better business practices, which in turn allow these countries to play a more influential role in the global production chains (Pacheco-López, 2005; Montobbio and Rampa, 2005). 


\section{The model}

This section deals with identifying some major determinants of Mexico's IMSs in the US. This exercise is carried out for 21 manufacturing subsectors over the 2007-2017 period. Moreover, three elements are considered in specifying the econometric model and the reference period (2007-2017): economic theory, prior empirical work, and the obtainability of disaggregated data. Although we clarify this point in the empirical analysis section, here it is necessary to underline that no disaggregated data are available for key technology-related variables, such as research and development (R\&D) expenditure. Nonetheless, drawing on Fagerberg (1988) and Riedel (1998), it was possible to formulate a parsimonious model consisting of supply- and demand-side variables, coupled with a control variable to address the omitted variable bias. First, let us highlight that Fagerberg (1988) specifies the following export function based on Schumpeter's (1943) approach:

$$
\frac{X_{t}}{Y_{t}^{*}}=\beta_{1} Q_{t}^{\beta_{2}}\left(\frac{T_{t}}{T_{t}^{*}}\right)^{\beta_{3}} C U_{t}^{\beta_{4}}
$$

where $X_{t}$ is the export volume at time $t, Y_{t}^{*}$ is the foreign income level, $Q_{t}$ is the real exchange rate, $\boldsymbol{U}{ }_{t}$ is capacity utilization, and $T_{t}$ and $T_{t}^{*}$ denote the domestic and foreign technological competitiveness, respectively. Moreover, $\beta_{1}$ is a proportionality parameter while $\beta_{2}, \beta_{3}$ and $\beta_{4}$ represent the elasticities of exports with respect to the real exchange rate, technological competitiveness and capacity utilization, respectively. As a dependent variable, many papers drawing on the Schumpeterian tradition replace the ratio of exports to foreign income level, $X_{t} / Y_{t}^{*}$, by the share of exports in world trade (Romero and McCombie, 2016, p. 7). We follow this approach, so that $X_{t} / Y_{t}^{*}$ becomes $X_{t} / M_{t}^{*}$, where $M_{t}^{*}$ is total US imports from the rest of the world. From the Mexican standpoint, US income level $\left(Y_{t}^{*}\right)$ and total US imports $\left(M_{t}^{*}\right)$ are both proxies for external demand, but the latter variable allows for the calculation of Mexico's IMSs in the US. In addition, there was no choice but to replace $T_{t}$ and $T_{t}^{*}$ by ULCs in Mexico and the US, respectively. The problem was that $T_{t}$ and $T_{t}^{*}$ are usually proxied by patents granted and R\&D expenditures and no disaggregated data are available for these two variables in the Mexican case, which prevents the estimation of a panel data model. In contrast, not only are there disaggregated data available for ULCs, but this variable can be regarded as a comprehensive measure of international cost competitiveness of industries as well as firms (OECD, 2017, p. 72). Under these circumstances, Equation (2) becomes: 


$$
\frac{X_{t}}{M_{t}^{*}}=\beta_{1} Q_{t}^{\beta_{2}}\left(\frac{U L C_{t}}{U L C_{t}^{*}}\right)^{\beta_{3}} C U_{t}^{\beta_{4}}
$$

where, as stated before, $M_{t}^{*}$ denotes total US imports from the rest of the world while $U L C_{t}$ and $U L C_{t}^{*}$ are unit labor costs in Mexico and the US, respectively. Given that $M_{t}^{*}$ allows for the estimation of Mexico's IMSs in the US, Equation (3) becomes:

$$
I M S_{t}=\beta_{1} Q_{t}^{\beta_{2}}\left(\frac{U L C_{t}}{U L C_{t}^{*}}\right)^{\beta_{3}} C U_{t}^{\beta_{4}}
$$

where $I M S_{t}=X_{t} / M_{t}^{*}$. Moreover, percentage capacity utilization $\left(\boldsymbol{U}_{t}\right)$ reflects changes in domestic demand for exportable manufactures, so that its inclusion is helpful in distinguishing between increases in IMSs resulting from lower-than-expected internal demand for tradable manufactures, on the one hand, and rises in IMSs coming from lower ULCs at home or higher ULCs abroad, on the other. This is the reason why some papers use capacity utilization as a control variable (Paiva, 2003; Berrettoni and Castresana, 2007). Moreover, percentage capacity utilization can also capture changes in the volume of manufacturing goods produced, in which case this variable might bear a positive relationship with IMSs. Next, it was deemed convenient for empirical purposes to separate the effect of domestic ULCs from the effect of foreign ULCs on Mexico's IMS in the US. Hence, Equation (4) becomes:

$$
I M S_{t}=\beta_{1} Q_{t}^{\beta_{2}} U L C_{t}^{\beta_{3}} U L C_{t}^{* \beta_{4}} C U_{t}^{\beta_{5}}
$$

To rewrite Equation (5) in terms of a standard panel regression model, we simply: (i) take logs on both sides of the equation, (ii) include a second subscript to acknowledge that we are dealing with several cross-section units, and (iii) incorporate a disturbance term. This exercise yields:

$$
i m s_{i t}=\beta_{1}^{\prime}+\beta_{2} q_{i t}+\beta_{3} u l c_{i t}+\beta_{4} u l c_{i t}^{*}+\beta_{5} c u_{i t}+u_{i t}
$$

where $\beta_{1}^{\prime}=\ln \beta_{1}$, the lower-case variables are simply the natural logs of the upper-case variables, and $u_{i t}$ is an error term. Moreover, subscripts $i$ and $t$ denote the cross-section unit (i.e., the industry) and the year, respectively, and the regression parameters can be interpreted as elasticities. In such a context, the data concerning IMSs in the US and the real exchange rate had to be calculated for each manufacturing sub-sector. The next equation allows for the 
possibility that industries are heterogeneous:

$$
i m s_{i t}=\beta_{1 i}^{\prime}+\beta_{2} q_{i t}+\beta_{3} u l c_{i t}+\beta_{4} u l c_{i t}^{*}+\beta_{5} c u_{i t}+u_{i t}
$$

where $\beta_{1 i}^{\prime}$ is an intercept term that can vary across industries. Equation (7) represents a balanced panel consisting of 231 observations, given that we are dealing with 21 industries $(N=21)$ of different technological ranking and 11 years $(T=11)$, ranging from 2007 to 2017. The industries analyzed here are: (i) food; (ii) beverages and tobacco; (iii) textile mills; (iv) textile product mills; (v) apparel; (vi) leather and allied products; (vii) wood products; (viii) paper; (ix) printing and related support activities; (x) petroleum and coal products; (xi) chemical manufacturing; (xii) plastics and rubber products; (xiii) nonmetallic mineral products; (xiv) primary metal manufacturing; (xv) fabricated metal product manufacturing; (xvi) machinery; (xvii) computer and electronic products; (xviii) electrical equipment and appliances; (xix) transportation equipment; (xx) furniture and related products; and (xxi) miscellaneous manufacturing. This classification differs to a certain extent from the one used to carry out the IMS analysis, but it allows us to increase substantially the number of cross-sections units and thus the number of observations to estimate the model.

\section{Empirical analysis}

\section{Data issues}

As stated before, Equation (7) is a balanced panel consisting of 231 observations in all, as we deal with 21 industries over the period 2007-2017. In the case of Mexico, this level of disaggregation can only be obtained from 2007 onward. Moreover, to produce time series from 2007 to 2017, it was necessary to match producer price indices (PPIs) with different base periods. In the case of the US, disaggregated data for ULSs is only available with annual periodicity. In the case of China, the lack of "reliable disaggregated data" for the manufacturing sector (Lett and Banister, 2009, p. 30) prevented us from including additional variables such as Chinese ULCs in our model. Finally, seeing that we have 21 cross-section units, we proceeded to construct a bilateral real exchange rate for each industry over the reference period. To that end, we used the peso-dollar interbank exchange rate and the appropriate components of the US and the Mexican PPIs. Thus, we provide a real exchange rate for each of the 21 manufacturing subsectors.

\section{Panel unit root tests}

As is well known, a panel spurious regression can arise when: (i) the variables involved are nonstationary, and (ii) they do not share a long-term or cointegrating relationship (Phillips and Moon, 1999). To reduce the risk of estimating a panel spurious regression, three 
types of panel unit root tests are performed: Levin, Lin, and Chu (2002), Im, Pesaran, and Shin (2003), and Fisher-type tests using the Augmented Dickey-Fuller (ADF) methodology (Maddala and $\mathrm{Wu}, 1999$ ). The Levin, Lin and Chu (LLC) test assumes that all series in the panel have a common unit root, whereas the other two tests assume that each series in the panel has an individual unit root. To specify each test equation (i.e., to decide whether to include an intercept and a trend or only an intercept) Hamilton's methodology (1994, p. 501) is utilized, meaning that each test equation must reflect the behavior of the time series. Tests results are shown in Table 3:

Table 3

Panel unit root tests

Probability values for the null hypothesis of unit root (or nonstationarity)

\begin{tabular}{ccccc}
\hline Variable & $\begin{array}{c}\text { Levin, Lin and } \\
\text { Chu Test }\end{array}$ & $\begin{array}{l}\text { Im, Pesaran and } \\
\text { Shin Test }\end{array}$ & $\begin{array}{l}\text { ADF-Fisher } \\
\text { Test }\end{array}$ & Conclusion \\
\hline$i m s_{i t}$ & 0.00 & 0.09 & 0.05 & $\mathrm{I}(0)$ \\
$q_{i t}$ & 0.10 & 0.98 & 0.99 & $\mathrm{I}(1)$ \\
$\Delta q_{i t}$ & 0.00 & 0.00 & 0.00 & $\mathrm{I}(0)$ \\
$u l c_{i t}$ & 0.00 & 0.10 & 0.08 & $\mathrm{I}(0)$ \\
$u l c_{i t}^{*}$ & 0.99 & 1.00 & 0.99 & $\mathrm{I}(1)$ \\
$\Delta u c_{i t}^{*}$ & 0.00 & 0.00 & 0.00 & $\mathrm{I}(0)$ \\
$\boldsymbol{c u}$ & 0.00 & 0.08 & 0.02 & $\mathrm{I}(0)$ \\
\hline
\end{tabular}

Notes: A probability value (or $p$-value) lower than 0.10 leads to the rejection of such a null hypothesis with at least a $90 \%$ confidence level. An individual intercept term, which account for individual fixed effects, is included in the test equation, given that the variables of the model have a positive mean and do not seem to involve individual linear trends. The Schwarz information criterion is used to determine the number of lags of the test equations.

Source: Own estimations based on data from the National Institute of Statistics and Geography (INEGI) of Mexico and the International Trade Administration of the US Department of Commerce.

Generally speaking, the picture that emerges from Table 3 is that Mexico's import market shares in the US $\left(i m s_{i t}\right)$, domestic unit labor costs $\left(u l c_{i t}\right)$ and capacity utilization $\left(c u_{i t}\right)$ 
are integrated of order $0(\mathrm{I}(0))$ or stationary. In the case of domestic unit labor costs $\left(u l c_{i t}\right)$, both the LLC and the ADF-Fisher tests lead to the rejection of the unit root null hypothesis at the $10 \%$ significance level, whereas the Im, Pesaran and Shin (IPS) test is on the very margin with a 0.10 probability value. Thus, the first two tests lead to reject the unit root hypothesis for this variable $\left(u l c_{i t}\right)$ with a confidence level exceeding $90 \%$, whereas the IPS test allows us to reject such a hypothesis with a $90 \%$ confidence level. On the other hand, the three tests are consistent in indicating that the peso-dollar real exchange rate $\left(q_{i t}\right)$ and the US unit labor costs $\left(u l c_{i t}^{*}\right)$ are integrated of order $1(\mathrm{I}(1))$ in levels and stationary in first differences. In such a context, we shall proceed to estimate a panel data model with stationary variables. In principle, our stationary panel data model would take the following form:

$$
i m s_{i t}=\beta_{1 i}^{\prime}+\beta_{2} \Delta q_{i t}+\beta_{3} u l c_{i t}+\beta_{4} \Delta u l c_{i t}^{*}+\beta_{5} c u_{i t}+u_{i t}
$$

where $\Delta$ is the first difference operator.

\section{Estimation method and empirical findings}

There are essentially three approaches to estimating a panel data model (Greene, 2008, p. 183). The first is the pooled regression model, which assumes that the industries are essentially homogeneous, thereby preventing the intercept term in Equation (8) from varying from one industry to another. The intercept term in this case would be simply denoted by $\beta_{1}$ , with no cross-section subscript. The second approach is the fixed effects (FE) model, which captures the latent heterogeneity among industries by including dummy variables of the 0,1 form. These dummies are useful in allowing the intercept term to change across industries. In Equation (8) the intercept term does vary across industries but to estimate these changes we must specify several dummy variables. Equation (9) reflects this transformation:

$$
i m s_{i t}=\alpha_{1}+\sum_{i=2}^{21} \alpha_{i} D_{i j}+\beta_{2} \Delta q_{i t}+\beta_{3} u l c_{i t}+\beta_{4} \Delta u l c_{i t}^{*}+\beta_{5} c u_{i t}+u_{i t}
$$

Given that we must capture the heterogeneity among 21 industries, Equation (9) includes 20 dummy variables of the 0,1 form with their corresponding parameters (i.e., $\sum_{i=2}^{21} \alpha_{i} D_{i j}$ ). Put differently, $\alpha_{1}$ is the point of reference and stands for the intercept term of industry 1 while $\alpha_{2}, \alpha_{3}, \ldots ., \alpha_{21}$ should be regarded as intercept differentials (e.g., $\boldsymbol{\alpha}_{1}+\boldsymbol{\alpha}_{2}$ would be the intercept of industry 2 and so on). Moreover, $D_{i j}$ equals 1 if we are dealing with industry $i$ $(i=2,3, \ldots, 21)$ and 0 otherwise.

Finally, the third approach is the random effects (RE) model, which is built upon the notion that the dummy variables in Equation (9) reflect a lack of knowledge regarding the right model specification. If that were the case, the heterogeneity across industries should be captured by the stochastic disturbance term (Kmenta, 1986, p. 633). As with the FE model, 
the RE model can in principle be represented by Equation (8), but the intercept term $\left(\boldsymbol{\beta}_{1 i}\right)$ must be thought of in a different way. Under the FE regression, $\beta_{1 i}^{\prime}$ takes on a fixed value for each cross-section unit. In contrast, under the RE approach $\beta_{1 i}^{\prime}=\beta_{1}^{\prime}+\varepsilon_{i}$, where $\varepsilon_{i}$ is a cross-section disturbance term having a constant variance and a zero mean. The underlying assumption of the RE model is that each cross-section unit was randomly extracted from a much larger population, whose average (or expected) value for the intercept term is given by $\beta_{1 i}^{\prime}$ while $\varepsilon_{i}$ stands for the stochastic deviation from the mean value reported by the ith cross-section unit. Rewriting Equation (8) in terms of the RE model, we get:

$$
i m s_{i t}=\beta_{1}^{\prime}+\beta_{2} \Delta q_{i t}+\beta_{3} u l c_{i t}+\beta_{4} \Delta u l c_{i t}^{*}+\beta_{5} c u_{i t}+v_{i t}
$$

where $v_{i t}=\varepsilon_{i}+u_{i t}$ is a compound error term consisting of a cross-section error $\left(\varepsilon_{i}\right)$ and an idiosyncratic error $\left(u_{i t}\right)$ that varies across individuals and across time. When industries are not fully homogeneous, the pooled regression is inadequate given that not all industries share the same intercept. As shown below, industries are heterogenous to a certain degree. On the other hand, the RE model is only suitable when the cross-section units are randomly selected from a much larger population (Wooldridge, 2001, p. 452), which is not the case as this paper is based on the whole universe of 21 manufacturing subsectors. Therefore, we proceed to estimate the FE model represented by Equation (9). The FE model allows all explanatory variables to be endogenous with respect to the individual random effects. Put differently, the FE model provides a consistent estimator of the coefficients of the stochastic regressors even if they are correlated with the latent heterogeneity (Baltagi, 2008, p. 22; Greene, 2008, p. 339). The next step is to estimate the following dynamic version of the FE model previously depicted by Equation (9):

$$
i m s_{i t}=\alpha_{1}+\sum_{i=2}^{21} \alpha_{i} D_{i j}+\sum_{k=1}^{3} \gamma_{k} i m s_{i t-k}+\beta_{2} \Delta q_{i t-1}+\beta_{3} u l c_{i t-1}+\beta_{4} \Delta u l c_{i t-1}^{*}+\beta_{5} c u_{i t-1}+u_{i t}
$$

Model (9') can be referred to as a FE dynamic panel data model, which takes on the specification that appeared to be more appropriate among several alternatives that were estimated and tested. Its main advantage is that the effects of the stochastic explanatory variables (i.e., $\Delta q_{i t-1}, u l c_{i t-1}, \Delta u l_{i t-1}^{*}$, and $c u_{i t-1}$ ) must now take account of the historic behavior of the dependent variable, which includes three consecutive lags on the right-hand site of the equation. Note that the four stochastic explanatory variables are lagged one period, which allows for capturing the time it takes for a change in the real exchange rate, domestic ULCs and foreign ULCs to affect IMSs. To estimate Equation (9'), we rely on Feasible Generalized Least Squares (FGLS) with cross-section weights. Such a method corrects for both serial 
correlation and cross-section heteroscedasticity in the residuals or, at least, lessens those problems to a certain degree. To further improve the efficiency of the parameter estimates, coefficient standard errors are computed through period weights Panel Corrected Standard Errors (PCSE) and covariances, which are robust to time-series heteroscedasticity (Beck and Katz, 1995). Table 4 shows the results of such an exercise:

Table 4

Estimated dynamic fixed effect (FE) model

Dependent variable: Mexico's import market share $\left(i m s_{i t}\right)$ of industry $i$ at time $t$

Estimation method: Feasible Generalized Least Squares (FGLS) with cross-section weights. Coefficient standard errors are computed through period weights Panel Corrected Standard Errors (PCSE)

\begin{tabular}{|c|c|c|c|}
\hline Variable & Coefficient & Variable & Coefficient \\
\hline$i m s_{i t-1}$ & $0.743 * * *$ & $D_{8 j}$ & $-1.777 * * *$ \\
\hline$i m s_{i t-2}$ & $-0.147 *$ & $D_{9 j}$ & $-1.086 * * *$ \\
\hline$i m s_{i t-3}$ & $0.137 * *$ & $D_{10 j}$ & $-2.635^{* * *}$ \\
\hline$\Delta q_{i t-1}$ & $-0.046^{* * * *}$ & $D_{11 j}$ & $-2.457 * * *$ \\
\hline$u l c_{i t-1}$ & $-0.007^{*}$ & $D_{12 j}$ & $-0.737 * *$ \\
\hline$\Delta u l c_{i t-1}^{*}$ & $0.021 * * *$ & $D_{13 j}$ & -0.052 \\
\hline$c u_{i t-1}$ & $0.018^{*}$ & $D_{14 j}$ & -0.308 \\
\hline$\alpha_{1}$ & $2.558 * *$ & $D_{15 j}$ & -0.137 \\
\hline$D_{2 j}$ & $1.918 * * *$ & $D_{16 j}$ & -0.426 \\
\hline$D_{3 j}$ & $-1.553 * * *$ & $D_{17 j}$ & 0.544 \\
\hline$D_{4 j}$ & $-2.386^{* * *}$ & $D_{18 j}$ & $3.106 * * *$ \\
\hline$D_{5 j}$ & $-2.173 * * *$ & $D_{19 j}$ & $4.081 * * *$ \\
\hline
\end{tabular}




\begin{tabular}{lccc}
\multicolumn{1}{c}{$D_{6 j}$} & $-1.902^{* * *}$ & \multicolumn{1}{c}{$D_{20 j}$} & $-1.511^{* * *}$ \\
\multicolumn{1}{c}{$D_{7 j}$} & $-2.906^{* * *}$ & \multicolumn{1}{c}{$D_{21 j}$} & $-1.391^{* * *}$ \\
\hline $\begin{array}{l}\text { Adjusted } R^{2} \\
\begin{array}{l}\text { Standard error of re- } \\
\text { gression }\end{array}\end{array}$ & 0.996 & \multicolumn{2}{c}{ F-Statistic } \\
\end{tabular}

Notes:

1. Asterisks $*, * *$, and $* * *$ denote statistical significance at the 10,5 and $1 \%$ significance levels, respectively.

2. $\alpha_{1}$ is the estimated constant term that constitutes the point of reference (i.e., the constant term for industry 1), whereas the estimated coefficients associated with $D_{2 j}, D_{3 j}, \ldots, D_{21 j}$ are the estimated differential intercepts for industries $2,3, \ldots, 21$, respectively.

Source: Own estimations based on data from the National Institute of Statistics and Geography (INEGI) of Mexico and the International Trade Administration of the US Department of Commerce.

Before interpreting the empirical evidence of Table 4, we must analyze the outcome of a battery of diagnostic residual tests. Residual autocorrelation, heteroscedasticity, and cross-section dependence (i.e., contemporaneous correlation) undermine the efficiency of the parameter estimates, whereas serious deviations from normality cast doubt on the validity of conventional significance tests. Table 5 displays the results of four types of standard tests: Wooldridge test for serial correlation, Likelihood Ratio (LR) test for heteroscedasticity, Pesaran CD cross-section dependence test, and Jarque-Bera (JB) normality test. The probability values in Table 5 indicate that the null hypotheses of homoscedasticity, normality and "no cross-section dependence" cannot be rejected at the 5\% nor at the $10 \%$ significance level. However, the probability value associated with the null hypothesis of "no first-order serial correlation" is 0.000 , thereby suggesting the presence of time series correlation.

Table 5

Diagnostic tests for the residuals

\begin{tabular}{ccc}
\hline Type of test & Null hypothesis & Probability value \\
\hline Wooldridge test for serial correlation & No first-order serial correlation & 0.000 \\
LR-test for heteroscedasticity & Homoscedasticity & 0.950
\end{tabular}


Pesaran CD cross-section dependence test
No cross-section dependence (correlation) in weighted residuals

Jarque-Bera (JB) normality test Normality

Source: Own estimations based on data from the National Institute of Statistics and Geography (INEGI) of Mexico and the International Trade Administration of the US Department of Commerce.

Due to the presence of residual autocorrelation and its implication in terms of efficiency loss, we resort to a second econometric method to obtain more robust empirical evidence: the Arellano-Bond dynamic panel Generalized Method of Moments (GMM). The Arellano-Bond GMM estimator is consistent, robust to endogeneity problems, and basically requires no information regarding the distribution of the error term (Arellano and Bond, 1991). These properties make conventional significance tests more reliable when we lack information regarding the behavior of the error term. A key feature of this estimation methodology is that it eliminates the heterogeneity among cross-section units by differencing all the variables of the model, regardless of whether they are I(1) or I(0). To briefly explain this point, let us assume that the starting model takes on the following functional form:

$$
i m s_{i t}=\sum_{k=1}^{p} \gamma_{k} i m s_{i t-k}+\beta_{2} q_{i t}+\beta_{3} u l c_{i t}+\beta_{4} u l c_{i t}^{*}+\beta_{5} c u_{i t}+v_{i t}
$$

where $v_{i t}=\mu_{i}+u_{i t}$, so that in this case $\mu_{i}$ captures the heterogeneity among countries. To simplify things, we rewrite Equation (11) as follows:

$$
i m s_{i t}=\sum_{k=1}^{p} \gamma_{k} i m s_{i t-k}+x_{i t}^{\prime} \beta+\mu_{i}+u_{i t}
$$

where $\gamma_{k}$ is a set of scalars, $x_{i t}^{\prime}=\left[q_{i t}, u l c_{i t}, u l c_{i t}^{*}, c u_{i t}\right]$ is $1 \times 4$ and $\beta=\left[\beta_{2}, \beta_{3}, \beta_{4}, \beta_{5}\right]^{\prime}$ is $4 \times 1$. Given that the estimated model in Table 6 includes only two lags of the dependent variable, Equation (12) becomes:

$$
i m s_{i t}=\gamma_{1} i m s_{i t-1}+\gamma_{2} i m s_{i t-2}+x_{i t}^{\prime} \beta+\mu_{i}+u_{i t}
$$

The fact that the dependent variable $\left(i m s_{i t}\right.$ ) is a function of $\boldsymbol{\mu}_{i}$ implies that the lagged dependent variables ( $i m s_{i t-1}$ and $i m s_{i t-2}$ ) are also a function of $\boldsymbol{\mu}_{i}$. Thus, we have in principle two regressors that are correlated with $\mu_{i}$. It can also be the case that $i m s_{i t-1}$, $i m s_{i t-2}$ and one or more variables in $x_{i t}$ are correlated with the second component of the 
error term $\left(u_{i t}\right)$. Under this scenario, we would have an endogeneity problem and thus the OLS estimator would be biased and inconsistent. The Arellano-Bond estimator solves the endogeneity problem by generating a set of instrumental variables that takes advantage of the orthogonality conditions that exist between the lags of the explanatory variables in levels (i.e., the lags of $i m s_{i t-1}, i m s_{i t-2}$ and $x_{i t}^{\prime}$ ) and the second component of the error term $\left(u_{i t}\right)$. To make the instrumental variables meet the orthogonality conditions, Arellano and Bond (1991) eliminate the individual effect $\left(\mu_{i}\right)$ by first differencing both sides of Equation (13):

$$
\Delta i m s_{i t}=\gamma_{1} \Delta i m s_{i t-1}+\gamma_{2} \Delta i m s_{i t-2}+\Delta x_{i t}^{\prime} \beta+\Delta u_{i t}
$$

After suppressing $\mu_{i}$, the instrumental variables must only be uncorrelated with $\Delta u_{i t}$. The next step is to create a set of instrumental variables in a sequential fashion according to the Arellano-Bond methodology, whose set of instruments is given by the appropriate lags of the dependent and independent variables in levels. These instruments are strongly correlated with the regressors and uncorrelated with the disturbance term, so that the endogeneity problem is resolved. In fact, when the number of cross-section units $(N)$ is greater than the number of periods $(T)$ as in this case, the Arellano-Bond estimator is not only free of endogeneity problems, but it is also consistent, asymptotically efficient and needs no information concerning the distribution of the error term (Arellano and Bond, 1991; Baltagi, 2008, pp. 147-155). Table 6 shows the results of this procedure:

Table 6

Estimated dynamic panel data model

Dependent variable: Mexico's import market share in first difference ( $\Delta i m s_{i t}$ ) of industry $i$ at time $t$

Estimation method: The Arellano-Bond Generalized Method of Moments. Coefficient standard errors are computed through white period standard errors and covariances

Variable Coefficient
$\Delta i m s_{i t}$
$0.634^{* * * *}$

$\Delta i m s_{i t-2}$

$-0.045 * * *$

$\Delta q_{i t}$

$-0.033^{* * * *}$ 

$\Delta u l c_{i t}$
$-0.014 * * *$
$\Delta u l c_{i t}^{*}$
$0.030^{* * *}$
$\Delta c u_{i t}$
$-1.50 \mathrm{E}-05$

Notes:

1. Asterisks *,**, and $* * *$ denote statistical significance at the 10,5 and $1 \%$ significance levels, respectively.

2. $\Delta$ is the first difference operator, meaning that all variables are in first differences.

Source: Own estimations based on data from the National Institute of Statistics and Geography (INEGI) of Mexico and the International Trade Administration of the US Department of Commerce.

Before interpreting the empirical findings, we must recall that every econometric method makes it necessary to treat variables in a somewhat different fashion. Along these lines, Tables 4 and 6 show that the estimation results are basically consistent across econometric techniques. First, the empirical evidence indicates that Mexico's IMSs in the US tend to fall after the peso-dollar real exchange rate depreciates. The estimated regression coefficient of the real exchange rate (which is represented by $\Delta q_{i t-1}$ in Table 4 and by $\Delta q_{i t}$ in Table 6) is negative and statistically significant at the $1 \%$ level. As we argue further below, this is consistent with the notion that a real depreciation of the peso lowers international competitiveness and IMSs in the US by way of making imported intermediate inputs, capital stock and technology more expensive in terms of domestic currency. Some earlier research suggests that the formation of GVCs and the increasing import-content of exports have transformed the relationship between currency depreciation and exports (Swarnali, Appendino, and Ruta, 2017; Cheng et al., 2016). By the same token, Chen (2017) shows that an undervalued exchange rate slows down R\&D activity and thus technological progress.

Second, Mexico's IMSs in the US are negatively related to domestic ULCs $\left(u l c_{i t-1}\right.$ in Table 4 and $\Delta u c_{i t}^{*}$ in Table 6) and positively related to US ULCs ( $\Delta u c_{i t-1}^{*}$ in Table 4 and $\Delta u l_{i t}^{*}$ in Table 6). Put differently, an increase in domestic ULCs makes Mexico less competitive while an increase in US ULCs makes it more competitive vis-à-vis its main trading partner. Third, the parameter estimate associated with percentage capacity utilization is only statistically significant when using FGLS with cross-section weights (see Table 4) and exhibits a positive sign, which is consistent with the notion that increased capacity utilization may exert a positive influence on IMSs by way of higher production levels. 
Finally, although the 21 industries operate in the same regulatory and institutional environment, they are not fully homogenous as the first econometric method shows (Table 4). The food industry serves as a point of reference and its estimated intercept (i.e., the estimate of $\boldsymbol{\alpha}_{1}$ ) is statistically significant at the $5 \%$ level. Moreover, the estimated differential intercepts for 15 out the 20 remaining industries are statistically significant at different levels. A plausible explanation for such a heterogeneity is that, as Lall (2000) points out, some industries require more complex and fast-changing technologies than others. Accordingly, some industries tend to hire more skillful workers and place more emphasis on education and training than others. An $F$-test for the joint hypothesis that the estimated differential intercepts equal zero (Ho: $\alpha_{2}=\alpha_{3}=, \ldots,=\alpha_{21}=0$ ) yields an $F$-statistic of 4.302 with 20 degrees of freedom (df) in the numerator and $140 \mathrm{df}$ in the denominator, which yields to the rejection of the null hypothesis with a $100 \%$ confidence level (i.e., with a probability value of 0.000 ). Thus, the $F$-test strongly suggests that the industries are heterogenous.

\section{Conclusions}

Broadly speaking, the data show that: (i) China's IMSs in the US grew faster than Mexico's over different time horizons, and (ii) China's IMS growth rates were noticeably more stable than Mexico's. In this regard, one important exception is the Mexican medium technology sector during the 2008-2017 period, which displayed a higher and more stable IMS growth rate than its Chinese counterpart. Furthermore, our econometric evidence suggests that an undervalued peso may not be an effective policy to regain international competitiveness, which is to some extent consistent with previous empirical research cited in this paper. In other words, the estimated model shows that a real depreciation of the peso-dollar exchange rate reduces rather than increases Mexico's IMSs in the US. Conventional economic theory contends that real currency depreciation makes exports cheaper in terms of foreign currency, thus strengthening international competitiveness and raising IMSs in the US. This is the demand-side effect of currency depreciation, which seems to interact with a supply-side effect of opposite sign stemming from the high import content of Mexican manufacturing exports. Put briefly, the implication is that the supply-side effect of currency depreciation tends to dominate the demand-side effect, mainly because of the heavy reliance of the Mexican manufacturing sector on imported intermediate inputs, not to mention capital stock and technology. In Table 4 the first difference of the subsector-specific real exchange rate is lagged one period (i.e., $\square q_{i \square \square}$ ) because the influence of import prices on export prices seems to be stronger after one year, which is consistent with the notion that the ability of firms to endure higher costs erodes as times progresses.

The net negative impact of real currency depreciation on IMSs in the US reflects the overwhelming reliance of the export-oriented manufacturing industries on global suppliers 
of intermediate inputs, capital stock and technology. In this context, a well-known policy prescription that continues to receive little attention is to establish efficient production chains between small- and medium-sized businesses producing for the domestic market, on the one hand, and large manufacturing exporters, on the other. A structural change in this direction could lessen to a certain degree the volatility of IMS growth rates by restraining the disruptive effect of currency depreciation.

An increase in domestic ULCs brings down IMSs in the US. This is consistent with the finding of Mbaye and Golub (2002) and Aysan and Hacihasanoglu (2007) in terms that higher ULCs discourage manufacturing exports. As is well known, the abatement of ULCs requires labor productivity to grow faster than wages, whereas the key to improve labor productivity is to invest more in human capital formation (Padilla and Juárez, 2007). In this perspective, education spending could contribute to reducing ULCs, strengthening manufacturing competitiveness, and increasing IMSs in the US. The responsiveness of IMSs to ULCs brings attention to the insufficient investment in formal education and job-related training. To provide the workforce with the appropriate knowledge, skills and abilities, the Mexican government should spend more rather than less on human capital formation. What is more, the Mexican government should spend better by addressing, in association with other relevant parties, the specific training requirements of each subsector of the manufacturing industry. Lastly, the estimation results show that a fall in US ULCs will lead to a reduction in Mexico's IMSs. The rationale here is that lower ULCs in the US allow US-made products to be more competitive vis-á-vis Mexican products, which in turn slows down Mexican sales in the US.

\section{Referencias}

Arellano, M., \& Bond, S. (1991). Some test of specification for panel data: Monte Carlo evidence and an application to employment equations. The Review of Economic Studies, 58(2), 277-297. https://doi.org/10.2307/2297968

Aysan, A. F., y Y. S. Hacihasanoglu (2007). Investigation on the determinants of Turkish export-boom in 2000s, MPRA Paper No. 5493, Munich Personal RePEc Archive Papers, Munich, BAV. Available at: https://mpra.ub.uni-muenchen.de/5493/ Accessed: 20/06/2019.

Baltagi, B. (2008). Econometric analysis of panel data. Chichester, WS: John Wiley \& Sons. Bayoumi, T., y B. Eichengreen (1997). Is Regionalism Simply a Diversion? Evidence from the EC and EFTA. In T. Ito y A. O. Krueger (Eds.), Regionalism versus multilateral trade arrangements (pp. 141-168). Chicago, IL: The University of Chicago Press. Available at: http://www.nber.org/chapters/c8599.pdf Accessed: 20/06/2019.

Beck, N., \& Katz, J. N. (1995). What to do (and not to do) with time-Series cross-section data. American Political Science Review, 89(3), 634-647. https://doi.org/10.2307/2082979 
Berrettoni, D., \& Castresana, S. (2007). Exportaciones y tipo de cambio real: el caso de las manufacturas industriales argentinas. Revista de Comercio Exterior e Integración, 9, 101-117. Available at: http://www.aaep.org.ar/anales/works/works2007/berrettoni.pdf Accessed: 20/06/2019.

Bougheas, S., Demetriades, P. O., \& Morgenroth, E. L. (1999). Infrastructure, transport costs and trade. Journal of International Economics, 47(1), 169-189. https://doi.org/10.1016/ S0022-1996(98)00008-7

Catão, L., \& Falsetti. E. (2002). Determinants of Argentina's external trade. Journal of Applied Economics, 5(1), 19-57. https://doi.org/10.1080/15140326.2002.12040570

Chen, S. S. (2017). Exchange rate undervaluation and R\&D activity. Journal of International Money and Finance, April (72), 148-160. https://doi.org/10.1016/j.jimonfin.2017.01.008

Cheng, K. C., Hong, G. H., Seneviratne, D., \& van Elkan, R. (2016). Rethinking the exchange rate impact on trade in a world with global value chains. International Economic Journal, 30(2), 204-216. https://doi.org/10.1080/10168737.2016.1148418

Fagerberg, J. (1988). International competitiveness. The Economic Journal, 98(391), 355374. http://doi:10.2307/2233372

Gallagher, K., Moreno-Brid, J. C., \& Porzecanski, R. (2007). The dynamism of Mexican exports: Lost in (Chinese) translation?. World Development, 36(8), 1365-1380. https:// doi.org/10.1016/j.worlddev.2007.08.004

Garcés, D. G. (2008). Análisis de las funciones de importación y exportación de México (1980-2000). El Trimestre Económico, 75(297), 109-141. http://www.jstor.org/stable/20857151

Gereffi, G. (2009). Development models and industrial upgrading in China and Mexico. European Sociological Review, 25(1), 37-51. https://doi.org/10.1093/esr/jcn034

Greene, W. H. (2008). Econometric analysis. Upper Saddle River, NJ: Pearson-Prentice Hall.

Hamilton, J. D. (1994). Time series analysis. Princeton, NJ: Princeton University Press.

Im, K. S., Pesaran, M. H., \& Shin, Y. (2003). Testing for unit roots in heterogeneous panels. Journal of Econometrics, 115(1), 53-74. https://doi.org/10.1016/S03044076(03)00092-7

Kmenta, J. (1986). Elements of econometrics. Ann Arbor, MI: University of Michigan Press.

Lall, S. (2000). The technological structure and performance of developing country manufactured exports, 1985 $\square 98$. Oxford Development Studies, 28(3), 337-369. https://doi. org/10.1080/713688318

Lett, E., \& Banister, J. (2009). China's manufacturing employment and compensation costs: 2002-06. Monthly Labor Review, April (4), 30-38. Available at: https://www.bls.gov/ opub/mlr/2009/04/art3full.pdf Accessed: 20/06/2019.

Levin, A., Lin, C. F., \& Chu, J. (2002). Unit root tests in panel data: asymptotic and finite-sample properties. Journal of Econometrics, 108(1), 1-24. https://doi.org/10.1016/ S0304-4076(01)00098-7 
Lin, Y. (2015). Is China relinquishing manufacturing competitiveness to Mexico in US markets?. World Economy, 23(4), 104-224. https://doi.org/10.1111/cwe.12123

Maddala, G. S., \& Wu, S. (1999). A comparative study of unit root tests with panel data and a new simple test. Oxford Bulletin of Economics and Statistics, 61(S1), 631-652. https:// doi.org/10.1111/1468-0084.0610s1631

Martínez-Zarzoso, I., \& Nowak-Lehmann, F. (2002). Augmented gravity model: An empirical application to MERCOSUR-European Union trade flows. Journal of Applied Economics, 6(2), 291-316. https://doi.org/10.1080/15140326.2003.12040596

Mbaye, A. A., \& Golub, S. (2002). Unit labor cost, international competitiveness, and exports: The case of Senegal. Journal of African Economies, 11(2), 219-248. https://doi. org/10.1093/jae/11.2.219

Menji, S. (2010). Export Performance and Determinants in Ethiopia, MPRA Paper No. 29427, Munich Personal RePEc Archive Papers, Munich, BAV. Available at: https:// ideas.repec.org/p/pra/mprapa/29427.html Accessed: 19/06/2019.

Mesquita, M. (2007). Fear of China: Is there a future for manufacturing in Latin America?. World Development, 35(3), 355-376. https://doi.org/10.1016/j.worlddev.2006.11.001

Montobbio, F., \& Rampa, F. (2005). The impact of technology and structural change on export performance in nine developing countries. World Development, 33(4), 527-547. https://doi.org/10.1016/j.worlddev.2005.01.001

Pacheco-López, P. (2005). Foreign direct investment, exports and imports in Mexico. The World Economy, 28(8), 1157-1172. https://doi.org/10.1111/j.1467-9701.2005.00724.x

Padilla, R., \& Juárez, M. (2007). Efectos de la capacitación en la competitividad de la industria manufacturera. Revista de la Cepal, May (92), 45-60. Available at: http://repositorio.cepal.org/bitstream/handle/11362/11191/092045060_es.pdf?sequence=1 Accessed: 19/06/2019.

Paiva, C. (2003). Trade elasticities and market expectations in Brazil, IMF Working Paper No. 140, International Monetary Fund, Washington, D.C. Available at: https://papers. ssrn.com/sol3/papers.cfm?abstract_id=879216 Accessed: 17/06/2019.

Phillips, P. C. B., \& Moon, H. R. (1999). Linear regression limit theory for nonstationary panel data. Econometrica, 67(5), 1057-1111. Available at: http://onlinelibrary.wiley. com/doi/10.1111/1468-0262.00070/full Accessed: 10/06/2019.

Reinhart, C. M. (1995). Devaluation, Relative prices, and International Trade: Evidence from Developing Countries, IMF Staff Papers No. 42, International Monetary Fund, Washington, D.C. Available at: https://link.springer.com/article/10.2307/3867574 Accessed: 15/05/2019.

Riedel, J. (1988). The demand for LDC exports of manufactures: Estimates from Hong Kong. The Economic Journal, 98(389), 138-148. Available at: http://www.jstor.org/stable/2233515 Accessed: 16/06/2019.

Rohlf, F. J. y R. R. Sokal (1995). Statistical tables. San Francisco, CA: Macmillan.

Romero, J. P., \& McCombie, J. S. L. (2016). Thirlwall's Law and the Specification of Export 
and Import Demand Functions: An Investigation of the Impact of Relative Productivity Growth on Trade Performance, CCEPP Working Paper No. 02, Cambridge Centre for Economic and Public Policy Working Papers Series, Cambridge, CAMBS. Available at: http://www.landecon.cam.ac.uk/research/real-estate-and-urban-analysis/centres/ccepp/ copy_of_ccepp-publications/WP1602.pdf Accessed: 16/06/2019.

Schumpeter, J. A. (1943). Capitalism, socialism and democracy. New York, NY: Harper.

Senhadji, A. S., \& Montenegro, C. E. (1999). Time-series Analysis of Export Demand Equations: A Cross-country Analysis, IMF Staff Papers No. 46, International Monetary Fund, Washington, D.C. Available at: https://link.springer.com/article/10.2307/3867643 Accessed: 16/06/2019.

Soloaga, I., \& Winters, A. (2001). Regionalism in the nineties: What effect on trade?. The North American Journal of Economics and Finance, 12(1), 1-29. https://doi.org/10.1016/ S1062-9408(01)00042-0

Swarnali, A., Appendino, S. M., \& Ruta, M. (2017). Global value chains and the exchange rate elasticity of exports. The BE Journal of Macroeconomics, 17(1), 1-24. https://doi. org/10.1515/bejm-2015-0130

Tinbergen, J. (1962). Shaping the world economy: Suggestions for an international economic policy. New York, NY: The Twentieth Century Fund.

Organization for Economic Cooperation and Development. (2017). Compendium of Productivity Indicators. Paris, FR: OECD. Available at: http://www.keepeek.com/Digital-Asset-Management/oecd/economics/oecd-compendium-of-productivity-indicators-2017_ pdtvy-2017-en\#.WSUgtWg1_IU\#page2 Accessed: 16/06/2019.

Wooldridge, J. M. (2001). Introducción a la econometría: Un enfoque moderno. Mexico City: Thomson Learning. 